\title{
PENGARUH DISIPLIN KERJA STAF DAN TENAGA PENGAJAR TERHADAP PENCAPAIAN VISI DAN MISI STIE MUJAHIDIN TOLITOLI
}

\section{THE EFFECT OF STAFF AND LECTURE DISCIPLINE ON THE ACHIEVEMENT OF THE VISION AND MISSION OF STIE MUJAHIDIN TOLITOLI}

\author{
${ }^{1}$ Suparman, ${ }^{2}$ Nur Hafifah Huzairah \\ ${ }^{12}$ Program Studi Manajemen, Sekolah Tinggi Ilmu Ekonomi Mujahidin \\ ${ }^{1}$ suparman@stiemujahidin.ac.id \\ ${ }^{2}$ nurhafifahhuzairah@gmail.com
}

\begin{abstract}
ABSTRAK
Sekolah Tinggi Ilmu Ekonomi (STIE) Mujahidin Tolitoli, merupakan salah satu perguruan tinggi swasta yang berada di Kabupaten Tolitoli, Provinsi Sulawesi Tengah, yang berdiri sejak tahun 2001 yang telah menghasilkan alumni terbaik yang bisa bersaing dengan lulusan dari perguruan tinggi lainnya namun masih memiliki keluhan dari mahasiswa tentang kinerja staf dan tenaga pengajar di perguruan tinggi tersebut. Tujuan penelitian ini adalah untuk mengetahui bagaimana pengaruh disiplin kerja staf dan tenaga pengajar terhadap pencapaian visi dan misi di STIE Mujahidin Tolitoli. Dalam penelitian ini, data diolah menggunakan analisis deskriptif dan kuantitatif yaitu skala likert untuk kebutuhan deskriptif dan analisis regresi linear sederhana untuk data kuantitatif. Hasil penelitian ini menunjukkan bahwa pengaruh antar dua variable terkait adalah $56 \%$ atau positif, yang berarti disiplin kerja menentukan pencapaian visi dan misi STIE Mujahidin Tolitoli, hubungan antara disiplin kerja terhadap pencapaian visi dan misi mempunyai hubungan searah. Kesimpulan dalam penelitian ini adalah bahwa disiplin kerja menentukan pencapaian visi dan misi pada STIE Mujahidin Tolitoli.
\end{abstract}

Kata Kunci: Disiplin kerja, Pengaruh, pencapaian visi dan misi

\section{ABSTRACT}

School of Economics Mujahidin Tolitoli, is a private university located in Tolitoli Regency, Central Sulawesi Province, which was founded in 2001 which has produced alumni best that can compete with graduates from other universities but still have complaints from students about the performance of staff and teaching staff at these colleges. The purpose of this study was to determine how the influence of staff and teaching staff work discipline on the achievement of the vision and mission at STIE Mujahidin Tolitoli. In this study, the data were processed using descriptive and quantitative analysis, namely the Likert scale for descriptive needs and simple linear regression analysis for quantitative data. The results of this study indicate that the influence between the two related variables is $56 \%$ or positive, which means that work discipline determines the achievement of the vision and mission of STIE Mujahidin Tolitoli, the relationship between work discipline and the achievement of vision and mission has a unidirectional relationship. The conclusion in this study is that work discipline determines the achievement of the vision and mission of STIE Mujahidin Tolitoli.

Keywords: Influence, work discipline, vision and mission achievement 


\section{PENDAHULUAN}

Sekolah Tinggi Ilmu Ekonomi (STIE) Mujahidin Tolitoli, merupakan salah satu perguruan tinggi swasta yang berada di Kabupaten Tolitoli, Provinsi Sulawesi Tengah, yang berdiri sejak tahun 2001 . Seperti halnya lembaga atau organisasi lainnya, STIE Mujahidin Tolitoli memiliki visi dan misi tersendiri. STIE Mujahidin Tolitoli memiliki dosen dan staf yang terdiri dari 47 orang tenaga pengajar dan 16 orang staf (non dosen) serta tercatat memiliki sebanyak 749 mahasiswa aktif pada tahun 2020. Selama 19 tahun berdiri, tentunya STIE Mujahidin Tolitoli telah menghasilkan alumni terbaik yang bisa bersaing dengan lulusan dari perguruan tinggi lainnya, sesuai dengan visi perguruan tinggi tersebut yaitu menjadi "Perguruan Tinggi Yang Unggul di Wilayah Sulawesi Tengah Dalam Menghasilkan Sumber Daya Manusia di Bidang Ekonomi Pada Tahun 2030".

Hasil diskusi dengan beberapa mahasiswa peneliti mendapatkan tanggapan adanya keluhan dari mahasiswa tentang kinerja staf dan tenaga pengajar di perguruan tinggi tersebut. Berdasarkan hasil diskusi diatas, maka penulis berinisiatif untuk melakukan observasi lanjut terkait hasil diskusi tersebut dengan metode wawancara. Berdasarkan hasil observasi, penulis mendapatkan keluhan yang sama dari mahasiswa lainya yang berlatar belakang kelas dan jurusan yang berbeda.

Tujuan penelitian ini adalah untuk mengetahui bagaimana pengaruh disiplin kerja staf dan tenaga pengajar terhadap pencapaian visi dan misi di STIE Mujahidin Tolitoli.

\section{Disiplin}

Singodimejo dalam Sutrisno (2009:85) mengatakan bahwa disiplin adalah sikap kesediaan dan kerelaan seseorang untuk mematuhi dan mentaati norma- norma peraturan yang berlaku disekitarnya. Siswanto Sastrohadiwiryo (2003:291) mengemukakan bahwa disiplin kerja dapat didefinisikan sebagai satu sikap menghormati, menghargai, patuh dan taat terhadap peraturan-peraturan kerja yang berlaku, baik yang tertulis maupun tidak tertulis serta sanggup menjalankannya dan tidak mengelak untuk menerima sanksi-sanksinya apa bila ia melanggar tugas dan wewenang yang diberikan kepadanya. Kedisiplinan adalah kesadaran dan kesediaan seseorang dalam mentaati semua peraturan perusahaan atau organisasi dan norma-norma sosial yang berlaku (Hasibuan, 2013:193).

\section{Indikator Disiplin Kerja}

Menurut Sutrisno (2009:67), terdapat empat indikator disiplin kerja, yaitu :

1. Taat terhadap aturan waktu. Dilihat dari jam masuk kerja, jam pulang, dan jam istirahat yang tepat waktu sesuai dengan aturan yang berlaku di perusahaan.

2. Taat terhadap peraturan perusahaan. Peraturan dasar tentang cara berpakaian, dan bertingkah laku dalam pekerjaan.

3. Taat terhadap aturan perilaku dalam pekerjaan. Ditunjukkan dengan caracara melakukan pekerjaan-pekerjaan sesuai dengan jabatan, tugas, dan tanggung jawab serta cara berhubungan dengan unit kerja lain.

4. Taat terhadap peraturan lainnya di perusahaan. Aturan tentang apa yang boleh dan apa yang tidak boleh dilakukan oleh para pegawai dalam perusahaan.

\section{Pembinaan Disiplin Kerja}

Adapun strategi dalam pembinaan disiplin kerja menurut Mulyasa dalam Muanifa S. Mahmud (2019:23) sebagai berikut :

1. Self-concept (konsep diri). Strategi ini menentukan bahwa konsep diri masingmasing individu merupakan faktor penting dari setiap perilaku. Untuk menumbuhkan konsep diri, pemimpin disarankan bersikap empati, menerima, hangat, dan terbuka, sehingga para 
tenaga kerja dapat mengeksplorasikan pikiran dan perasaannya dalam memecahkan masalah.

2. Communication skills (keterampilan berkomunikasi). Pemimpin harus menerima semua perasaan tenaga kerja dengan komunikasi yang dpat menimbulkan kepatuhan dari dalam dirinya.

3. Natural and logical consequences (konsekuensi-konsekuensi logis dan alami). Perilaku-perilaku yang salah terjadi karena tenaga kerja telah mengembangkan kepercayaan yang salah terhadap dirinya. Hal ini mendorong munculnya perilakuperilaku salah yang disebut "misbehavior". Untuk itu disarankan kepada pemimpin agar menunjukkan secara tepat tujuan perilaku yang salah, sehingga membantu tenaga kerja dalam mengatasi perilakunya tersebut, serta memanfaatkan akibat-akibat yang logis dan alami dari perilaku yang salah.

4. Values clarification (klarifikasi nilai). Strategi ini dilakukan untuk membantu tenaga kerja dalam menjawab pertanyaannya sendiri tentang nilainilai dan membentuk sistem nilainya sendiri.

\section{Visi dan Misi}

Visi adalah Visi adalah suatu pandangan jauh tentang perusahaan, tujuan-tujuan perusahaan dan apa yang harus dilakukan untuk mencapai tujuan tersebut pada masa yang akan datang (Aditya, 2010)

Misi adalah Misi adalah pernyataanpernyataan yang mendefinsikan apa yang sedang/akan dilakukan atau ingin dicapai dalam waktu (sangat) dekat atau saat ini (Arman, 2008).

\section{METODE}

Jenis penelitian ini menggunakan metode deskriptif, dengan pendekatan kuantitatif, analisis yang berfungsi untuk mengetahui kemungkinan sebab-akibat atau memberi gambaran terhadap objek yang di teliti melalui data primer dan data sekunder yang telah di peroleh dari berbagai literatur yang berkaitan. Penelitian ini dilakukan di STIE Mujahidin Tolitoli dengan waktu penelitian selama 4 bulan terhitung sejak bulan Januari sampai dengan bulan April 2021. Adapun jumlah populasi dalam penelitian ini adalah sebanyak 749 mahasiswa, 47 orang tenaga pengajar dan 14 orang staf non dosen. Teknik pengambilan sampel dalam penelitian ini adalah purposive sampling. Purposive sampling adalah teknik pengambilan sampel sumber data dengan pertimbangan tertentu.

Pengumpulan data dilakukan dengan 3 metode yaitu observasi, kuesioner dan dokumentasi. Dalam penelitian ini, data diolah menggunakan analisis deskriptif dan kuantitatif dengan menggunakan pengukuran skala Likert untuk kebutuhan pengolahan data deskriptif. Skala likert adalah skala yang digunakan untuk mengukur sikap, pendapat, dan presepsi seseorang atau sekelompok orang tentang fenomena sosial. Kemudian analisis kuantitatif dilakukan dengan menggunakan Analisis regresi linear sederhana untuk menguji sejauh mana sebab akibat antara variabel faktor penyebab $(\mathrm{X})$ dan variabel akibatnya (Y) untuk menjelaskan pengaruh disiplin kerja staf dan tenaga pengajar terhadap pencapaian visi dan misi di STIE Mujahidin Tolitoli. Analisis ini dihitung dengan menggunakan rumus sebagai berikut :

$$
Y=a+b x
$$

Keterangan :

$\mathrm{Y}=$ Disiplin Kerja

$\mathrm{x}=$ Pencapain Visi dan Misi

$\mathrm{a}=$ Konstanta

$\mathrm{b}=$ Koefisien Regresi

\section{HASIL DAN PEMBAHASAN}

Berdasarkan hasil pengolahan kuesioner, bahwa tanggapan responden atas kuesioner yang dibagikan tentang disiplin kerja staf (non dosen) antara staf Program Studi Manajemen, Program Studi Ekonomi Pembangunan, BAA, BAU, 
LPPM, LPM, dan Perpustakaan, dengan skor jawaban tertinggi yaitu disiplin krja Staf Program Studi Ekonomi Pembangunan dengan total skor 2042 dengan rata- rata persentase $17 \%$, kemudian Staf Perpustakaan dengan total skor 1919 dengan rata-rata persentase $17 \%$, kemudian staf BAU dengan total skor 1912 dengan rata-rata persentase $17 \%$, kemudian staf LPM dengan total skor 1905 dengan persentase $17 \%$ kemudian staf BAA dengan total skor 1892 dengan rata-rata persentase 16\%, kemudian staf LPPM dengan total skor 1869 dengan persentase 17\%, kemudian staf Program Studi Manajemen dengan total skor 1866 dengan persentase $16 \%$.

Kemudian, pengaruh antar dua variable yang diukur selanjutnya diolah menggunakan analisis regresi linear sederhana dengan hasil Nilai $\mathrm{Y}=$ 56.166.449 atau $56 \%$ atau positif, yang berarti disiplin kerja menentukan pencapaian visi dan misi STIE Mujahidin Tolitoli. Nilai a = konstanta yaitu 88,8347 adalah positif berarti hubungan antara disiplin kerja terhadap pencapaian visi dan misi mempunyai hubungan searah. Sedangkan hasil $b=$ koefisien regresi yaitu $25,141.739$ berarti disiplin kerja 25,141,739 berpengaruh terhadap pencapaian visi dan misi di STIE Mujahidin Tolitoli.

\section{KESIMPULAN DAN SARAN}

Adapun kesimpulan dalam penelitian ini adalah bahwa disiplin kerja menentukan pencapaian visi dan misi pada STIE Mujahidin Tolitoli. Selain itu, terdapat hubungan positif yang berarti hubungan antara disiplin kerja terhadap pencapaian visi dan misi mempunyai hubungan searah serta variabel disiplin kerja berpengaruh kuat terhadap pencapaian visi dan misi di STIE Mujahidin Tolitoli.

\section{UCAPAN TERIMAKASIH}

Kami mengucapkan terimakasih kepada STIE Mujahidin Tolitoli yang telah memperikan ruang dan kesempatan kepada kami untuk melaksanakan penelitian ini. Tak lupa pula kami ucapkan terimakasih kepada Fakultas Ekonomi Universitas Indonesia Timur yang telah memberikan kami sarana untuk mempublikasikan hasil penelitian kami.

\section{DAFTAR PUSTAKA}

Aditya, A. 2010. Visi dan Misi

Perusahaan. Jakarta: Gramedia Pustaka.

Anto Tulim. 2019 Pengaruh Disiplin, Motivasi dn Lingkungan Kerja Terhadap Kinerja Karyawan Pada PT. Perusahaan Air Minum (PDAM) Cabang Medan Danai.

Arman, S., (2008), Visi Dan Misi Perusahaan, The Global Source for Summaries \& Reviews.

Hasibuan. 2013. Dalam Adnan. 2019.

Pengaruh Disiplin Kerja Dan Produktifitas Kerja Terhadap Kinerja Pegawai Pada Bidang Meteorology, Kimatologi, dan Geofisika (BMKG) Jakarta.

Made Subudi. 2019. Pengaruh Disiplin Kerja, Gaya Kepemimpinan, dan Motivasi Kerja Terhadap Kinerja Karyawan Pada Hotel Matahari Terbit Bali Tanjung Benoa-Nusa Dua.

Muanifa S. Mahmud. 2019. Analisis Disiplin Kerja Karyawan Pada Koperasi Jaya Abadi Kabupaten Buol.

Nursyam, N., \& Rahmawati, D. (2021). The Effect of Work Motivation on Employee Performance at the Office of Manpower and Transmigration of South Sulawesi 
Province. Economy Deposit Journal (E-DJ), 2(2).

Siswanto Sastrohadiwiryo. 2003. Dalam

Herdiana. 2012. Analisis Disiplin

Kerja Pegawai Pada Bagian

Keuangan Rumah Sakit Umum

(RSU) Mokopido Kabupaten

Tolitoli

Sutrisno. 2009. Dalam Herdiana. 2012.

Analisis Disiplin Kerja Pegawai

Pada Bagian Keuangan Rumah

Sakit Umum (RSU) Mokopido

Kabupaten Tolitoli. 